\title{
Erratum to: Criteria of the German Society of Cardiology for the establishment of chest pain units: update 2015
}

\author{
Felix Post ${ }^{1} \cdot$ Tommaso Gori $^{2} \cdot$ Evangelos Giannitsis $^{3} \cdot$ Harald Darius $^{4}$. \\ Stephan Baldus ${ }^{5}$. Christian Hamm ${ }^{6}$. Rainer Hambrecht ${ }^{7} \cdot$ Hans Martin Hofmeister $^{8}$. \\ Hugo Katus $^{3} \cdot$ Stefan Perings $^{9} \cdot$ Jochen Senges $^{10} \cdot$ Thomas Münzel $^{2}$
}

Published online: 28 January 2016

(c) Springer-Verlag Berlin Heidelberg 2016

\section{Erratum to: Clin Res Cardiol (2015) 104:918-928 DOI 10.1007/s00392-015-0888-2}

Unfortunately, an error occurred in the title of the above named article published in Clinical Research in Cardiology (2015) 104:918-928.

The correct title reads as follows:

Criteria of the German Society of Cardiology for the establishment of chest pain units: update 2015

We apologize for any inconveniences caused.

The online version of the original article can be found under doi:10.1007/s00392-015-0888-2.

Thomas Münzel

tmuenzel@uni-mainz.de

1 Katholisches Klinikum Koblenz Montabaur, Koblenz, Germany

2 II. Medizinische Klinik und Poliklinik für Kardiologie, Angiologie und internistische Intensivmedizin, Universitätsmedizin Mainz, Langenbeckstr. 1, 55131 Mainz, Germany

3 Klinik für KardiologieAngiologie und Pneumonologie, Heidelberg, Germany

4 Department für Kardiologie, Innere Medizin und Intensivmedizin, Vivantes-Klinikum Neukölln, Berlin, Germany
Klinikum III für Innere Medizin Uniklinik Köln, Cologne, Germany

6 Kerkhoff-Klinik, Bad Nauheim, Germany

7 Klinik für Kardiologie und Angiologie, Herzzentrum Bremen, Bremen, Germany

8 Kardiologie und allgemeine Innere Medizin, Solingen, Germany

9 Cardiozentrum, Düsseldorf, Germany

10 Institut für Herzinfarktforschung, Ludwigshafen, Germany 